\title{
The Making Process of Go/CT/PTFE Flat Sliding Plate of High-Speed Railway Bridge Spherical Bearings
}

\author{
Li-hu Wang, Shou-ren Wang*, Dao-sheng Wen, Gao-qi Wang and Pei-wen Wang \\ School of Mechanical Engineering, Jinan University, China
}

Submission: July 02, 2018; Published: August 02, 2018

*Corresponding author: Shou-ren Wang, School of Mechanical Engineering, Jinan University, China, Email: sherman0158@tom.com

\begin{abstract}
According to the rapid development of high-speed railway, the importance of spherical bridge bearings has attracted lots of attention as an essential connected part between bridge and pillar [1,2]. As you know, high-speed railway spherical bearings consist of upper bearings plate, spherical plate, under plate, flat stainless-steel plate, flat sliding plate, spherical stainless steel plate, spherical sliding plate, sealing ring, anchor bolt, dustproof shield [3,4]. Flat sliding plate is an indispensable part of spherical bearings since the displacement ability of bearings is determined by the sliding behavior between flat stainless-steel plate and flat sliding plate.
\end{abstract}

Keywords: Spherical bridge; Steel plate; Sealing ring; Cold pressing

\section{Mini Review}

Now the flat plate is made of PTFE, which is categorized as a chemical polymer and usually called "the king of plastic". As PTFE has a great ability of friction and wear, it has been used widely. However, PTFE behave badly in creep deformation resistance unless adding to original PTFE extra material which could improve the performance to against creep deformation. One of the well-known extra adding materials is GO [5,6]. GO is a kind of two-dimension nanometer material with hive-like flat thin film, which is made of sp2 and found in 2004. Although GO is as thick as one carbon atom, it has high level yield strength and stiffness, great lubricant performance and excellent wearresistance attribute, and it means that GO could reduce friction coefficient if it mixes with PTFE $[7,8]$. Another adding material called CF which also has high level yield strength and elasticity and could be added to PTFE to improve the wear resistance of material. But, both GO and CF show low compatibility with PTFE as adding material and many scholars and experts have focused on this phenomenon. In this paper, it shows a new kind of making process of Go/CF/PTFE flat sliding plate of high-speed railway bridge spherical bearings by $\mathrm{KH}-550$

\section{Weighing Material and Mixing Material}

The experimental material is weighed by electronic universal analytical balance and then placed in grinding room of planetary ball mill. The parameters are showed below.

Grinding time: 240 minutes, rotate rate: $180 \mathrm{r} / \mathrm{min}$, the ratio of ball to sample: 7:1

\section{Cold Pressing}

Put the sample into mold (Figure 1), and then Universal hydraulic forming machine could press the sample. With $10 \mathrm{MPa} /$ min press velocity, the load pressure should increase gradually to $130 \mathrm{MPa}$ and stay for 10 minutes, to make sure the air among the sample could be expelled entirely.
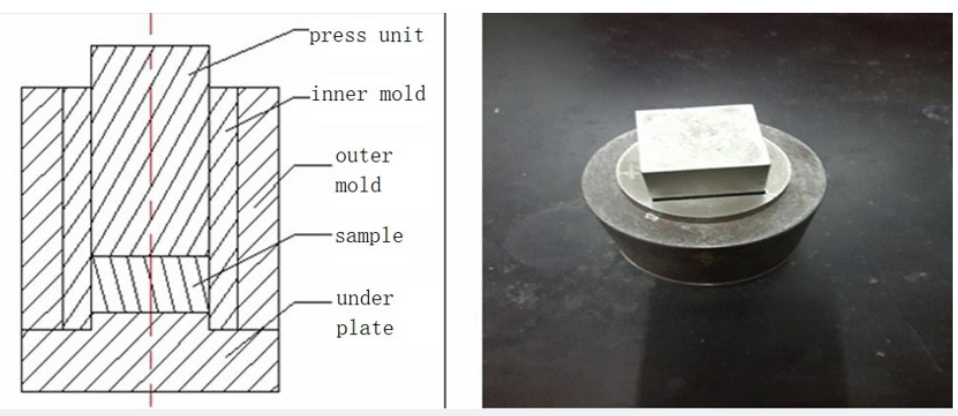

Figure 1: Cold pressing mold. 


\section{Sintering Solidification}

After cold pressing process, the sample should be placed into electric furnace for sintering. Figure 2 shows process flow diagram. With $60{ }^{\circ} \mathrm{C} / \mathrm{h}$ heating velocity, the sample should be heated up to $327^{\circ} \mathrm{C}$, which is the melting point of the sample, and then keep the temperature for 30 minutes. And then the sample should be heated up to $375^{\circ} \mathrm{C}$ and keep the temperature for 2 hours. After furnace cooling process, the sample could be considered well-prepared [9].

\section{Microstructure Analysis}
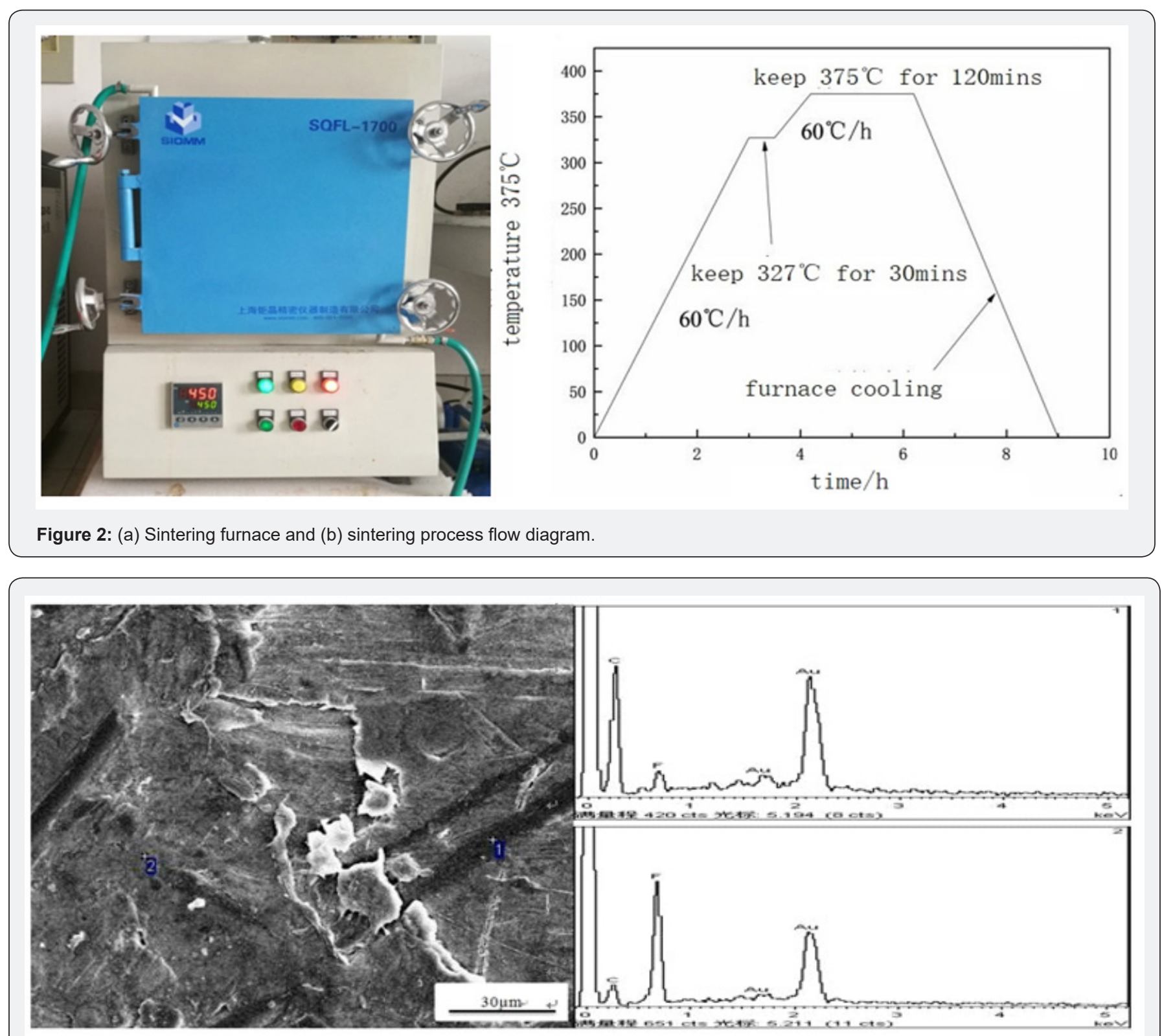

Figure 3: Sample S's spot scanning of energy spectrum.

After making process of flat sliding plate, microstructure analysis could be completed. Figure 3 shows sample S's spot scanning of energy spectrum and Figure 4 shows sample S's map scanning of energy spectrum. In Figure 3, area 1 shows trace of black strip, which is CF, and area 2 shows matrix material. Figure 4 also shows that $\mathrm{CF}$ has been distributed evenly in the matrix material, and it means than CF has relatively good compatibility and it could improve some kinds of strength property of sliding plate sample [10]. Figure 5 shows the impact section microstructure of composite sample. We can conclude that the interface issue was not good from area 1 in Figure 5. 

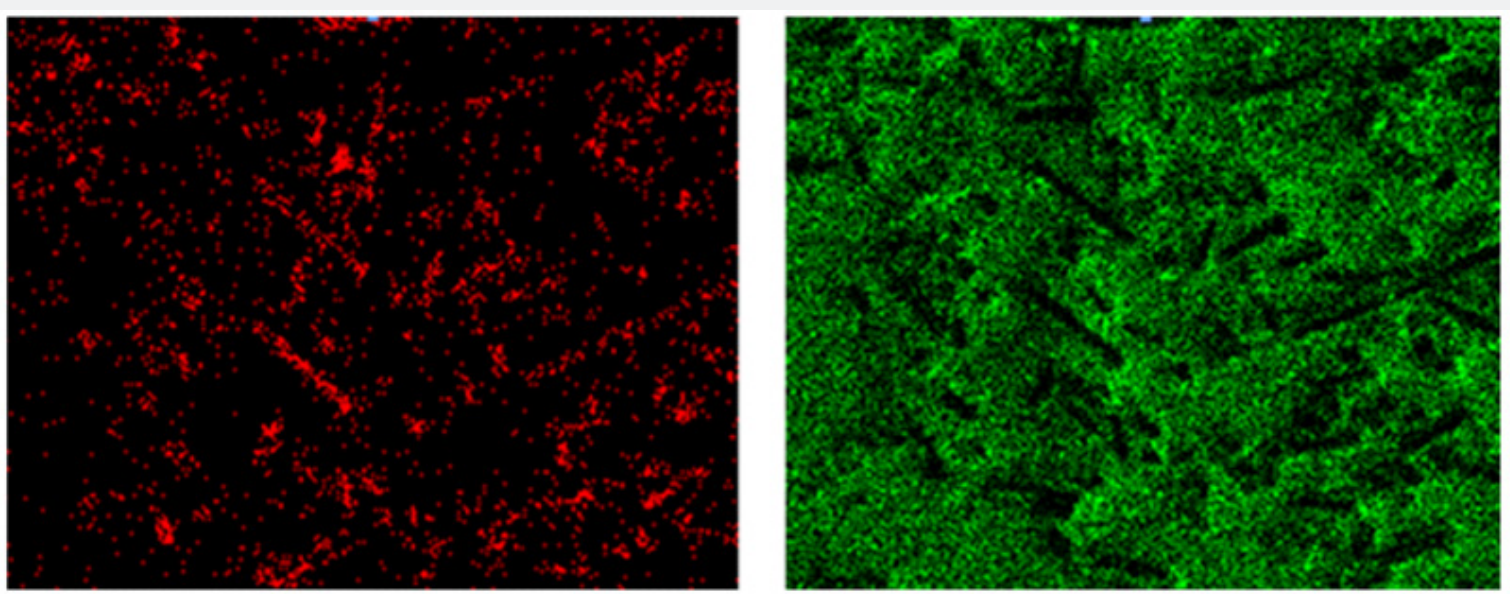

Figure 4: Sample S's map scanning of energy spectrum (a) CF(red trace); (b)matrix (green trace).
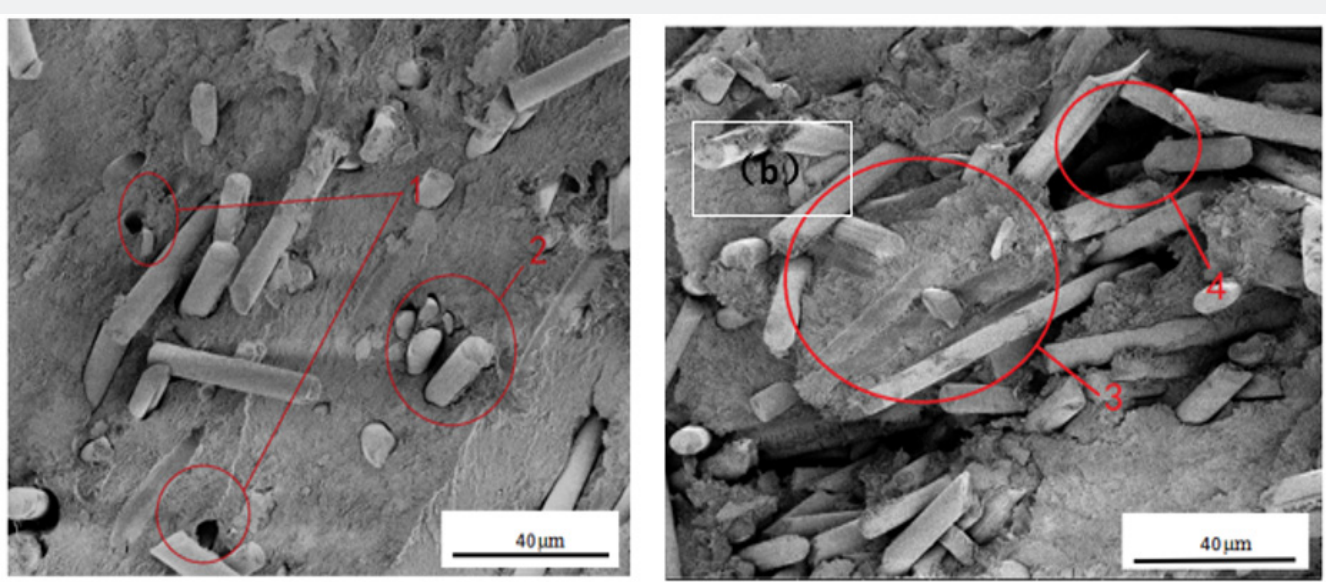

Figure 5: Composites Specimen Impact Section(a) CF losening; (b) CF aggregat.

CF was extracted out from the material when it was impacted. The combination between CF and matrix would turn to be loose. Maybe it was caused by the incomplete disposition by silane coupling agent, or the silane coupling agent disposition couldn't improve the interface issue between CF and PTFE. The tight combination between $\mathrm{CF}$ and matrix which is shown on area 3 in Figure 5, which proved that the interface issue was solved seemingly. What is shown on area 2 in Figure 5 is that the mid area of CF has been broken, which proved that $\mathrm{CF}$ could strengthen the matrix. Area 4 in Figure 5 has shown the gaps in composite material sample. Maybe it was caused by the fast compressing rate of cold-press molding, or the liquid evaporation during sintering process which was attributed to the halfway drying of sample.

\section{Conclusion}

Bearings' sliding plate sample could be made by cooling press process and sintering solidification successfully, and since CF could be distributed evenly among matrix, it illustrates that $\mathrm{CF}$ could reduce wear and friction for material.

\section{References}

1. Li Jun (2006) Structural design of super large tonnage ball bearing. Chongqing: Chongqing University.

2. Zhuang Jun Sheng (2015) Bridge support. ( $3^{\text {rd }}$ edn). China Railway Publishing House, Beijing, China.

3. Zhang Meng, Xie Feng, Li Bin (2015) Effects of organic fillers on the tribological properties of PTFE. synthetic lubricants 45(1): 16-18.

4. Xiao Jun, Fan Huitao, Fan Lai (2011) The preparation of modified carbon fiber reinforced polytetrafluoroethylene composite materials. polymer materials science and engineering 27(4): 132-134.

5. Zhu Enbo (2010) Preparation and properties of reinforced PTFE composites filled with fiber and powder filler. Jiangsu: Jiangsu University.

6. Fan Qing, Ye Sujuan (2008) Study on Tribology of graphite and fiber filled PTFE Composites. lubrication and sealing 33(5): 86-88.

7. Beckford S, Mathurin L, Chen J, Fleming RA, Min Zou (2016) The effects of polydopamine coated $\mathrm{Cu}$ nanoparticles on the tribological properties of polydopamine/PTFE coatings. Tribology International 103: 87-94.

8. Conte M, Igartua A (2012) Study of PTFE composites tribological behavior. Wear 296(1-2): 568-574. 
9. Jotaki K, Miyatake M, Stolarski T, Shinya Sasaki, Shigeka Yoshimoto (2016) Tribological performance of natural resin urushi containing PTFE. Tribology International 113: 291-296.

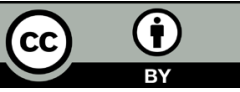

This work is licensed under Creative Commons Attribution 4.0 License

DOI: 10.19080/AJOP.2018.01.555566
10. Wang Lihu, Wang Shouren, Wang Peiwen (2017) Preparation and Tribological Properties of plane sliding plate of GO/CF/PTFE high iron bridge spherical support. Shandong science 30(3): 45-50.

\section{Your next submission with Juniper Publishers will reach you the below assets}

- Quality Editorial service

- Swift Peer Review

- Reprints availability

- E-prints Service

- Manuscript Podcast for convenient understanding

- Global attainment for your research

- Manuscript accessibility in different formats

( Pdf, E-pub, Full Text, Audio)

- Unceasing customer service

Track the below URL for one-step submission https://juniperpublishers.com/online-submission.php 